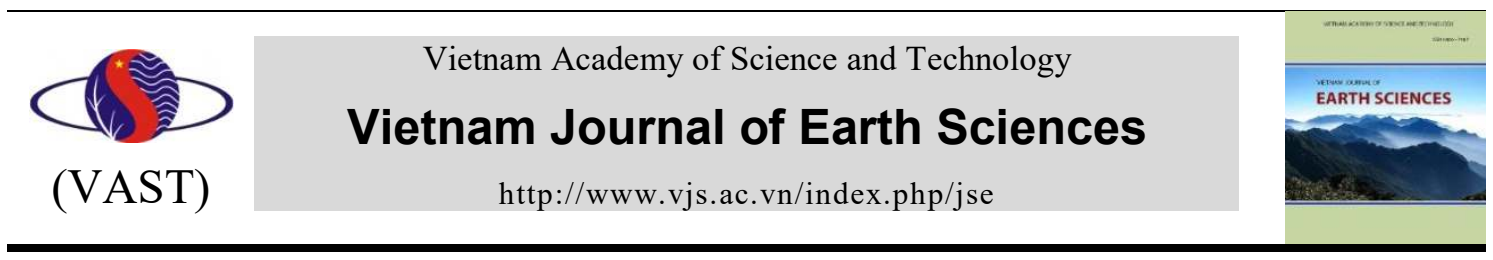

\title{
The relation between fault movement potential and seismic activity of major faults in Northwestern Vietnam
}

\author{
Bui Van Duan, Nguyen Anh Duong* \\ Institute of Geophysics (VAST)
}

Received 23 February 2017. Accepted 5 June 2017

\begin{abstract}
In this study, the method of Fault Movement Potential (FMP) proposed by Lee et al. (1997) is used to assess the movement potential of some major faults and its relationship with the seismic activities in Northwestern Vietnam. The fault movement potential is assessed by the magnitude of FMP (from 0 to 1 ) and calculated based on the relationship between kinematic characteristics of the faults and regional tectonic stress field. The maximum compressive stress axis in Northwestern Vietnam has the nearly horizontal trend (7.4 \pm 4.0$)$ and the direction of 170.2 \pm 6.7 . The calculated results of FMP at 60 geological survey points along major faults in Northwestern Vietnam show that the movement potential of these faults is mainly from medium to high $(40 / 60$ points with FMP $=0.6-0.9)$. In particular, the faults in Dien Bien Phu have the highest movement potential (FMP $=0.8-0.9$ ). An earthquake catalog that consists of 177 earthquakes with $\mathrm{M}=4.0$ - 6.8 occurring in the studied area from 1277 to 2016 is used to assess the relationship between seismic activities and fault movement potential. The research results indicate that at the locations on the faults with high movement potential, seismic activities occur frequently. On the segment of Son La fault zone in Tuan Giao, Tua Chua, the movement potential has the highest value (FMP $=0.9$ ), corresponding to the occurrence of Tuan Giao earthquake with $\mathrm{M}=6.8$ in 1983. On the contrary, weak earthquake or even no earthquake occur at the locations with low movement potential such as the segment of Son La fault in Moc Chau, Yen Chau, the segment of Ma River fault in Lang Chanh and the Than Uyen fault in Than Uyen. With the complete survey dataset on slip surface attitude of faults in contemporary times, FMP is significant for assessing the level of seismic activities on each part of the faults, serving the segmentation of faults, establishment of seismogenic regions, earthquake prediction and seismic hazard assessment.
\end{abstract}

Keywords: Northwestern Vietnam, active fault, fault movement potential, tectonic stress field, earthquake, seismic activity.

C2017 Vietnam Academy of Science and Technology

\section{Introduction}

Spatial and temporal manifestations of intraplate earthquakes are often different from those of the earthquakes occurring at the

*Corresponding author, Email: duongnaigp@yahoo.com boundaries of tectonic plates. At the plate boundaries, after the large earthquakes, the energy is rapidly accumulated in the tectonic displacement to continue causing other earthquakes. Therefore, the locations of recent earthquakes and the average time intervals be- 
tween them are consistent with the evolution of faults in terms of geology and seismology. Meanwhile, intraplate earthquake activities are often associated with intraplate faulting activities (e.g. Tuttle et al., 2002; Nguyen Dinh Xuyen et al., 2004a; Nguyen Ngoc Thuy et al., 2005a). The occurrence of great earthquakes in the stable continental regions clearly demonstrates that a significant amount of elastic strain energy is accumulated and released within the geological structures far from the plate boundaries.

The geological structure in Northwestern Vietnam is complicated with the major fault zones such as Son La fault, Ma River fault, Lai Chau - Dien Bien fault, Da River fault and Red River fault. These fault zones are likely to generate the greatest earthquakes in Vietnam. From 1900 until now, some large earthquakes have occurred in the studied area, particularly the Dien Bien earthquake with $\mathrm{M}=6.7$ in the $\mathrm{Fu}$ May Tun fault zone in 1935, the Tuan Giao earthquake with $M=6.8$ in the Son La fault zone in 1983. These two earthquakes produced the strong shakings on a large scale, caused the landslides, destroyed the houses and made several dozen people dead and injured (Nguyen Ngoc Thuy et al., 2005a).

In the geodynamic model of Southeast Asia, the Red River fault is considered as the northeast tectonic boundary between the South China block and the Sunda block (Simons et al., 2007). However, the greatest earthquakes have not occurred at this boundary but on the faults such as Fu May Tun and Son La in Northwestern Vietnam (Nguyen Dinh Xuyen et al., 2004a; Phan Trong Trinh et al., 2012). It may be because Northwestern Vietnam is located in the transitional area between the South China block, Sunda block and Baoshan sub-block (Findlay and Phan Trong Trinh, 1997; Nguyen Anh Duong et al., 2013).
Northwestern Vietnam is considered as the most seismic active region in Vietnam; consequently, many in-depth studies on active faults and earthquakes have been conducted in this region. The fault segmentation was first studied in Vietnam in 1994 (Winter et al., 1994). In 2013, Phan Trong Trinh and his colleagues conducted the fault segmentation along the Red River and Ca River fault zones in Hoa Binh, facilitating the maximum earthquake assessment (Phan Trong Trinh et al., 2013). The comprehensive researches on tectonic faults and geodynamics in Northwestern Vietnam that use the methods of geomorphology, geology, remote sensing, tectonophysics and structural lineaments are typically (Nguyen Van Hung, 2002). In these researchers, the major fault zones in Northwestern Vietnam have been determined along with their characteristics such as fault dynamics, geomorphology, geology, structure, movement mechanism, movement velocity, long-term historic evolution, etc. In addition, some detailed studies on the specific fault zone or fault segments in a small area have been carried out. Van Duc Tung (2011) studied the tectonic - geodynamic characteristics, segmentation and tectonic evolution of Lai Chau - Dien Bien fault zone. The author pointed out that this fault zone has undergone 5 phases of tectonic deformation since the Early - Middle Jurassic and has 3 segments in Vietnam's territory. Ngo Van Liem studied the geomorphological processes and tectonic activities in the Red River and Chay River fault zones. As a result, 44 basins in the Con Voi mountain range have been categorized into three typical shapes: straight-shaped, S-shaped and concave.

The synthesis of research results of active faults in many studies has allowed updating, supplementing and detailing the catalog of active fault systems in Northwestern Vietnam. Accordingly, many studies on seismic hazard assessment have been conducted. Typically, 
Nguyen Ngoc Thuy et al. (2005a) carried out the detailed seismic zoning in Northwestern Vietnam, concentrated on the seismic microzoning for 7 urban areas in this region.

The regional and Vietnam seismic station networks have recorded several large earthquakes in Northwestern Vietnam along with their aftershocks such as the Dien Bien earthquake with $\mathrm{M}=5.3$ on Lai Chau - Dien Bien fault in 2001, the Bac Yen earthquake (Son La) with $\mathrm{M}=3.9$ on Muong La - Bac Yen fault in 2009, the Quan Son earthquake (Thanh Hoa) with $\mathrm{M}=4.2$ on Son La fault in 2010, the Sop Cop earthquake (Son La) with $\mathrm{M}=4.8$ on Ma River fault in 2010. The determination of earthquake focal mechanisms has contributed to clarifying the regional tectonic setting. A number of studies on the earthquake focal mechanisms in the major fault zones in Northwestern Vietnam have been conducted based on the methods of moment tensor inversion according to broadband seismic data (Ha Thi Giang, 2012), direction of P-first motions observed at each station (Le $\mathrm{Tu}$ Son, 2000; 2004) and macroseismic field modeling (Nguyen Van Luong, 1996). The study results show that the fault zones in Northwestern Vietnam mostly have the strikeone in studying contemporary tectonic stress field. The centralization and systematism of the orientation in focal mechanisms are the basis for establishing the average stress field in a region. Nguyen Van Luong and Bui Cong Que (1997) used the methods of the direction of P-first motions and macro seismic field modeling to determine the focal mechanisms of 81 earthquakes in Vietnam and adjacent regions. The analysis of tectonic stress field in Northwestern Vietnam shows that the compressive and tensile stresses are nearly horizontal in the north-south and east-west directions, respectively. Phan Trong Trinh (2012) identified the contemporary tectonic stress field in the East Vietnam Sea and adjacent areas through 1291 stress indicators, including the data on borehole breakouts, drillinginduced fractures, focal mechanisms and young geological features. Also, the relationships between the distribution of contemporary tectonic stress field and the forces at tectonic boundaries as well as the intraplate forces induced by topography, geomorphology of sedimentary basins and local structures were analyzed. The results indicate that the maximum horizontal compression axis of the regional stress field is in the north-northwest south-southeast to northwest - southeast directions.

Although many in-depth studies on active faults and earthquakes in Northwestern Vietnam have been carried out, they have only dealt with the qualitative relationship between seismic activities and active faults. In this article, the method of Lee et al. (1997) is used to evaluate the movement potential along the major fault zones in Northwestern Vietnam and its relationship with the seismic activities based on the correlation between kinematic characteristics of faults and contemporary tectonic stress field.

\section{Method and Data}

\subsection{Method}

According to Lee et al. (1997), the fault movement potential (FMP) is considered to be strongly correlated with the tectonic stress field $(\sigma)$, the geometry characteristics of faults (G) and the physical properties of the medium inside and on the faults (P). FMP is a function of these parameters and expressed as follows:

$$
\mathrm{FMP}=\mathrm{f}(\sigma, \mathrm{G}, \mathrm{P})
$$


The geological medium is generally heterogeneous and complicated; however, in terms of statistics, in the theory of Lee et al. (1997), he considered the medium within the faults to be homogeneous, isotropic and elastic. Therefore, the formula (1) is simplified as follows:

$$
\mathrm{FMP}=\mathrm{f}(\sigma, \mathrm{G})
$$

To investigate the effect of tectonic stress field (in terms of direction) and geometric features of faults on seismic activities, Lokajicek et al. (1988) conducted the experiments using block models. The results show that the changes in dip angle of faults lead to the significant changes in the time interval between the earthquakes and seismic energy. Additionally, the seismic activities of faults

$$
\text { FMP }=\left\{\begin{array}{l}
0 \\
\frac{\theta-60^{\circ}}{30^{\circ}} \\
1-\frac{\theta-60^{\circ}}{30^{\circ}}
\end{array}\right.
$$

where $\theta$ is the angle between the direction of maximum principal compressive stress axis $\left(\sigma_{1}\right)$ and the normal of fault plane. $\theta$ is determined by the following expression: $\cos \theta=\cos \beta_{1} \cos \beta_{2} \cos \left(\gamma_{1}-\gamma_{2}\right)+\sin \beta_{1} \sin \beta_{2} \quad$ (4)

$\gamma_{1}$ - Direction of the normal of fault plane; $\beta_{1}$ - Dip angle of the normal of fault plane;

$\gamma_{2}$ - Direction of maximum principal compressive stress axis; $\beta_{2}$ - Dip angle of maximum principal compressive stress axis.

The maximum principal compressive stress axis $\left(\sigma_{1}\right)$ of regional tectonic stress field is usually determined by the analysis result of focal mechanism, while the normal of fault plane is determined according to the attitude of fault plane measured in the field. The faults have the highest movement potential when $\mathrm{FMP}=1$ and no movement potential when $\mathrm{FMP}=0$. do not occur at some certain values of dip angle. Subsequently, He (1989) performed the theoretical analyses to demonstrate the laboratory results and indicated that the faults can slip when the angle between the maximum principal compressive stress axis and the strike of fault is from $20^{\circ}$ to $70^{\circ}$. However, these experimental models were implemented in two-dimensional space, resulting in a great difference from the actual fault system. To overcome this limitation, Lee et al. (1997) studied the problem in three-dimensional space by using the theories of Mohr's stress circle and normalized FMP to quantify the fault movement potential. FMP is expressed as follows:

$$
\begin{aligned}
& \theta \in\left[0^{\circ}, 30^{\circ}\right] \\
& \theta \in\left(30^{\circ}, 60^{\circ}\right] \\
& \theta \in\left(60^{\circ}, 90^{\circ}\right]
\end{aligned}
$$

\subsection{Data}

\subsubsection{The normal of fault plane}

Northwestern Vietnam has the differentiated topography with high mountains and is dissected by many tectonic faults (Figure 1). These faults have been studied in detail in the previous studies and assessed to be active in the neotectonic and contemporary tectonic stages (e.g. Nguyen Van Hung, 2002; Nguyen Van Hung and Hoang Quang Vinh, 2004; Nguyen Van Vuong et al., 2004; Nguyen Ngoc Thuy et al., 2005a, b; Nguyen Anh Duong et al., 2011; Van Duc Tung, 2011; Phan Trong Trinh et al., 2013). These faults have developed on the basis of ancient faults and acted as the boundaries between tectonicstructural units with different movement mechanisms. The majority of major faults in the studied area 
extends in the northwest - southeast (NW-SE) direction, only a small minority extends in the northeast - southwest (NE-SW) and sublongitudinal directions. A common feature of the movement mechanism of faults in the late stage (Pliocene - present) is the dominance of strike-slip mechanism for all major fault zones, of which the Lai Chau - Dien Bien fault zone is sinistral strike-slip and the NWSE fault zones are mainly dextral strike-slip. Moreover, the sub-latitudinal extensional ac- tivities of the sub-longitudinal neotectonic fracture zones under normal mechanism in the contemporary stage have occurred quite strongly (Tran Van Thang et al., 2012). The common features of tectonic deformation are the dextral strike-slip and differentiated normal extensional movements which are clearly demonstrated by the morphology of faults in the studied area in contemporary geodynamic conditions.

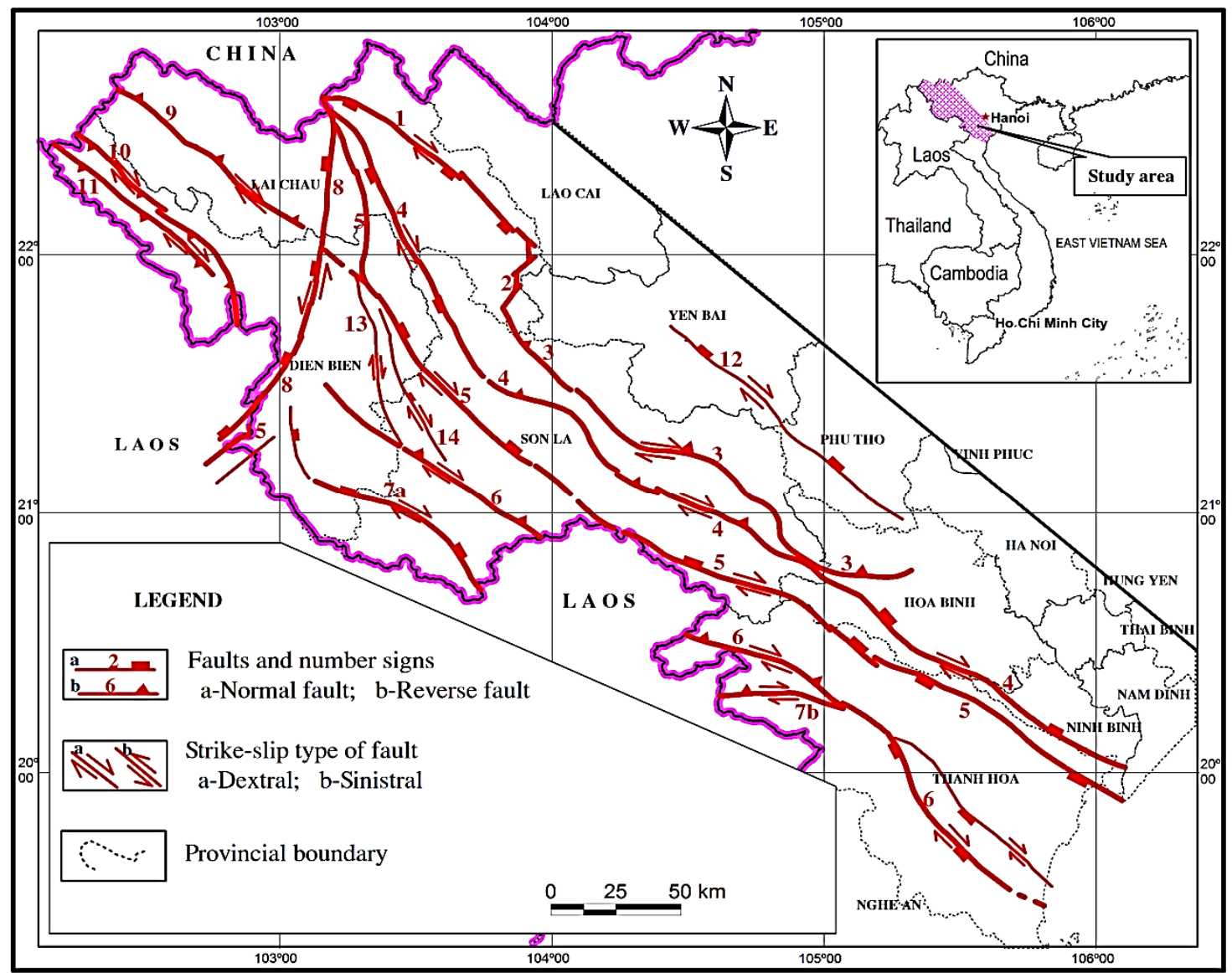

Figure 1. Active faults in Pliocene - present in Northwestern Vietnam

1- Phong Tho, 2- Than Uyen, 3 - Muong La - Bac Yen - Cho Bo, 4- Song Da, 5- Son La, 6- Ma River, 7a- Fu May Tun, 7b- Quan Son, 8- Lai Chau - Dien Bien, 9- Upper Da River, 10- Muong Toong, 11- Muong Nhe, 12- Nghia Lo Hoa Binh, 13- Bung Lao - Da Bop, 14- Tuan Giao - Nam Ty, 15- Dien Bien - Pac Nua

To assess the movement potential on major faults in the studied area under the effect of contemporary tectonic stress field, we have used a dataset on slip surface attitude of the 
Bui Van Duan, Nguyen Anh Duong/Vietnam Journal of Earth Sciences 39 (2017)

faults in the Pliocene - present at 60 survey points in the studies of Nguyen Van Hung, 2002; Nguyen Dinh Xuyen et al., 2004b; Nguyen Ngoc Thuy et al., 2006; 2008 and Bui Van Duan, 2012. The locations of survey points are shown in Figure 2. With these survey points, the normals of fault planes in the studied area corresponding to each slip surface attitude have been calculated and presented in Table 1.

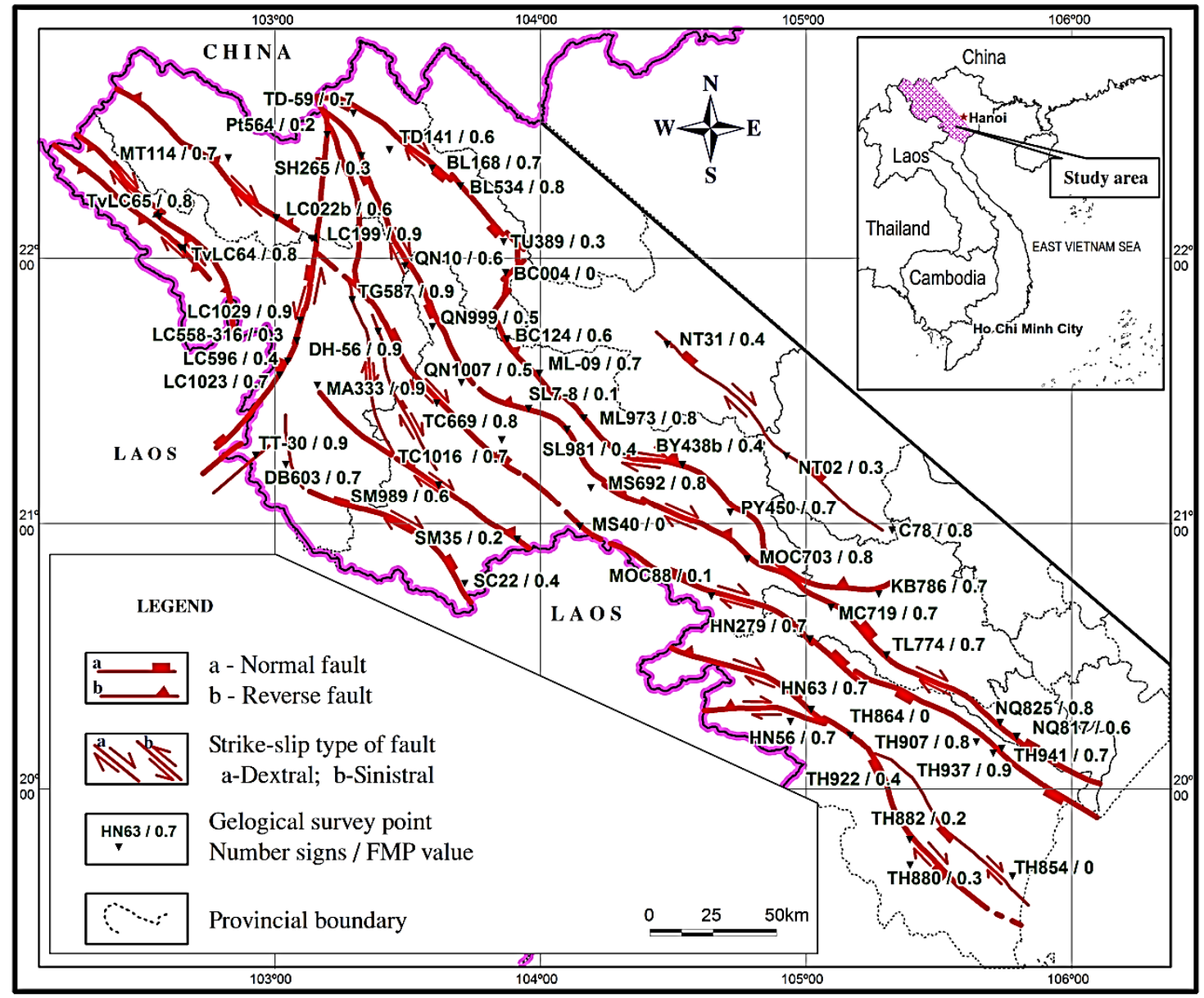

Figure 2. Locations and values of FMP of 60 geological survey points in Northwestern Vietnam

Table 1. Results of movement potentials of major faults in Northwestern Vietnam

\begin{tabular}{|c|c|c|c|c|c|c|c|}
\hline \multirow[b]{2}{*}{ Fault } & \multirow[b]{2}{*}{ Survey point } & \multicolumn{2}{|c|}{ Attitude of fault } & \multicolumn{2}{|c|}{ Normal line of fault plane } & \multirow[b]{2}{*}{$\begin{array}{l}\theta^{(*)} \\
\left({ }^{\circ}\right)\end{array}$} & \multirow[b]{2}{*}{ FMP } \\
\hline & & $\begin{array}{l}\text { Azimuth of } \\
\text { dip direction } \\
\left({ }^{\circ}\right)\end{array}$ & $\begin{array}{c}\text { Dip angle } \\
\left(^{\circ}\right)\end{array}$ & $\begin{array}{c}\text { Azimuth of } \\
\text { normal line } \\
\left(^{\circ}\right)\end{array}$ & $\begin{array}{c}\text { Dip angle } \\
\left(^{\circ}\right)\end{array}$ & & \\
\hline \multirow{5}{*}{ Phong Tho } & TD-59 & 40 & 75 & 220 & 15 & 53 & 0.7 \\
\hline & TD141 & 50 & 50 & 230 & 40 & 72 & 0.6 \\
\hline & BL168 & 40 & 80 & 220 & 10 & 51 & 0.7 \\
\hline & BL534 & 225 & 68 & 45 & 22 & 53 & 0.8 \\
\hline & TU389 & 70 & 80 & 250 & 10 & 80 & 0.3 \\
\hline Than Uyen & $\mathrm{BC} 004$ & 334 & 80 & 154 & 10 & 25 & 0.0 \\
\hline
\end{tabular}


Vietnam Journal of Earth Sciences, 39(3), 240-255

\begin{tabular}{|c|c|c|c|c|c|c|c|}
\hline & ML-09 & 40 & 80 & 220 & 10 & 51 & 0.7 \\
\hline & ML973 & 40 & 70 & 220 & 20 & 55 & 0.8 \\
\hline Muong La - Bac Yen - & BC124 & 60 & 75 & 240 & 15 & 71 & 0.6 \\
\hline \multirow[t]{8}{*}{ Cho Bo } & BY438b & 10 & 60 & 190 & 30 & 42 & 0.4 \\
\hline & PY450 & 54 & 63 & 234 & 27 & 69 & 0.7 \\
\hline & KB786 & 30 & 60 & 210 & 30 & 53 & 0.7 \\
\hline & SH 265 & 70 & 80 & 250 & 10 & 80 & 0.3 \\
\hline & QN10 & 60 & 70 & 240 & 20 & 72 & 0.6 \\
\hline & MC719 & 40 & 80 & 220 & 10 & 51 & 0.7 \\
\hline & QN999 & 34 & 79 & 214 & 11 & 46 & 0.5 \\
\hline & QN1007 & 60 & 60 & 240 & 30 & 75 & 0.5 \\
\hline \multirow{11}{*}{ Song Da } & SL7-8 & 10 & 70 & 190 & 20 & 33 & 0.1 \\
\hline & SL981 & 30 & 80 & 210 & 10 & 42 & 0.4 \\
\hline & MS692 & 240 & 80 & 60 & 10 & 67 & 0.8 \\
\hline & MOC703 & 55 & 80 & 235 & 10 & 65 & 0.8 \\
\hline & NQ817 & 36 & 81 & 216 & 9 & 47 & 0.6 \\
\hline & TL774 & 54 & 60 & 234 & 30 & 71 & 0.7 \\
\hline & NQ825 & 50 & 60 & 230 & 30 & 67 & 0.8 \\
\hline & TC669 & 40 & 70 & 220 & 20 & 55 & 0.8 \\
\hline & TC1016 & 40 & 80 & 220 & 10 & 51 & 0.7 \\
\hline & MS40 & 200 & 80 & 20 & 10 & 28 & 0.0 \\
\hline & TH907 & 240 & 79 & 60 & 11 & 67 & 0.8 \\
\hline \multirow[t]{9}{*}{ Son La } & TH937 & 236 & 68 & 56 & 22 & 63 & 0.9 \\
\hline & TH941 & 40 & 75 & 220 & 15 & 53 & 0.7 \\
\hline & TG587 & 50 & 90 & 230 & 0 & 58 & 0.9 \\
\hline & MOC88 & 20 & 80 & 200 & 10 & 33 & 0.1 \\
\hline & HN279 & 55 & 70 & 235 & 20 & 68 & 0.7 \\
\hline & MA333 & 50 & 70 & 230 & 20 & 64 & 0.9 \\
\hline & SM35 & 70 & 60 & 250 & 30 & 84 & 0.2 \\
\hline & SM989 & 60 & 72 & 240 & 18 & 72 & 0.6 \\
\hline & TH864 & 201 & 78 & 21 & 12 & 29 & 0.0 \\
\hline \multirow[t]{5}{*}{ Song Ma } & TH854 & 200 & 80 & 20 & 10 & 28 & 0.0 \\
\hline & TH922 & 63 & 63 & 243 & 27 & 77 & 0.4 \\
\hline & HN63 & 40 & 80 & 220 & 10 & 51 & 0.7 \\
\hline & TH882 & 72 & 72 & 252 & 18 & 83 & 0.2 \\
\hline & TH 880 & 72 & 77 & 252 & 13 & 82 & 0.3 \\
\hline \multirow{2}{*}{ Fu May Tun } & DB603 & 40 & 80 & 220 & 10 & 51 & 0.7 \\
\hline & $\mathrm{SC} 22$ & 30 & 80 & 210 & 10 & 42 & 0.4 \\
\hline \multirow{3}{*}{ Fu May run } & Pt564 & $270^{-}$ & 72 & 90 & 18 & 85 & 0.2 \\
\hline & LC596 & 275 & 80 & 95 & 10 & 79 & 0.4 \\
\hline & LC1023 & 305 & 80 & 125 & 10 & 50 & 0.7 \\
\hline \multirow{3}{*}{ Lai Chau - Dien Bien } & LC199 & 290 & 90 & 110 & 0 & 62 & 0.9 \\
\hline & LC1029 & 290 & 90 & 110 & 0 & 62 & 0.9 \\
\hline & LC558-316 & 90. & 85 & 270. & 5 & 81 & 0.3 \\
\hline \multirow{2}{*}{ Upper Da River } & MT114 & 40 & 80 & 220 & 10 & 51 & 0.7 \\
\hline & LC022b & 220 & 90 & 40 & 0 & 49 & 0.6 \\
\hline Muong Nhe & TVLC64 & $240^{\circ}$ & 80 & 60 & 10 & 67 & 0.8 \\
\hline \multirow[t]{2}{*}{ Muong Toong } & TVLC65 & $240^{-}$ & 80 & 60 & 10 & 67 & 0.8 \\
\hline & NT31 & $215^{-}$ & 80 & 35 & 10 & 42 & 0.4 \\
\hline \multirow{2}{*}{ Nghia Lo - Hoa Binh } & NT02 & 210 & 80 & 30 & 10 & 38 & 0.3 \\
\hline & C78 & 240 & 80 & 60 & 10 & 67 & 0.8 \\
\hline Tuan Giao-Nam Ty & DH-56 & 53 & 85 & 233 & 5 & 62 & 0.9 \\
\hline Dien Bien - Pac Nua & TT- 30 & 298 & 75 & 118 & 15 & 58 & 0.9 \\
\hline Quan Son & $\mathrm{HN} 56$ & 35 & 70 & $215^{-}$ & 20 & 51 & 0.7 \\
\hline
\end{tabular}

$(*) \theta$ is the angle between the direction of maximum principal compressive stress axis $\left(\sigma_{1}\right)$ and the normal line of fault plane 
2.2.2. Maximum principal compressive stress axis in Northwestern Vietnam

The compressive or tensile stress field is generated by the movement of lithospheric plates in the convergence or divergence forms, respectively. This movement induces a tectonic force field that propagates in the plates and is called the regional tectonic stress field. It does not remain in a certain form but changes according to time, space and magnitude (Andeweg et al., 1999). The contemporary tectonic stresses in geological structural units at varied locations are different; however, they still carry the typical morphology of regional tectonic stress field. The local force fields cause the local stresses which can alter the regional stress field. The local stresses possibly result from the movement of magma in active volcanic areas (Roman and Heron, 2007), the topography and density heterogeneities in the Earth's crust (Mandal et al., 1997), the incremental stresses due to the reservoir loading (Bui Van Duan et al., 2015).

The methods of conjugate joint set and superposition of compressive-tensile regions on the chart were used to determine the direction of maximum compressive stress axis (Nguyen Trong Yem, 1996). Angelier et al. (1982) calculated the stress tensor by minimizing the difference between horizontal stress and slip vectors observed on the fault surface based on the principle of Bott (1959). Bott (1959) established a mathematical model to clarify all types of faults on the assumption that the movement direction on the fault surface corresponded to the direction of maximum horizontal stress on this fault. McKenzie (1969) identified the relationship between earthquake focal mechanism and stress tensor, essentially the same as the correlation of Bott (1959); however, this is an important finding for determining the tectonic stress field based on earthquake focal mechanisms. Phan Trong Trinh (1993) used the inverse problem solution based on a set of striations on the fault planes and focal mechanisms in a specific region to determine the most appropriate stress tensor. This method can also be used to separate the different tectonic phases.

The tectonic stress field in Northwestern Vietnam from the Pliocene to present has the nearly horizontal compressive stress axis $\left(\sigma_{1}\right)$ in the sub-longitudinal direction (Nguyen Trong Yem, 1996; Tingay et al., 2010). The results of the paleostress analysis in Ma River area in Findlay and Phan Trong Trinh (1997) also show that the axis $\sigma_{1}$ orientated from the north-northwest to the northeast is dominant. The stress perturbation often occurs around the major faults in a seismic cycle and affects the change in direction of higher-order fault zones (Maerten et al., 2002). In the modern stage, the data on earthquake focal mechanisms (the large earthquakes on major faults) is a reliable indicator for evaluating the regional tectonic stress field. The earthquake focal mechanisms are mainly regulated by the tectonic stress field; in other words, the tectonic stress field is reflected in the picture of earthquake focal mechanisms (Phan Trong Trinh, 1993). One of the simplest methods for determining the values of stress axes of contemporary tectonic stress field is based on the results of earthquake focal mechanism analysis (Sorbi et al., 2009; Moghimi et al., 2015). According to earthquake focal mechanisms in the studied area (Table 2), the direction and dip angle of average attitude of the axis $\sigma_{1}$ in Northwestern Vietnam are calculated as $170.2 \pm 6.7^{\circ}$ and $7.4 \pm 4.0^{\circ}$ respectively (Figure $3)$. This result is consistent with the previous studies. Tingay et al. (2010) evaluated the contemporary tectonic stress field in Southeast Asia, in which the direction of maximum horizontal stress axis has a value of $173^{\circ}$ in Khorat (Thailand) that does not change significantly in Northwestern Vietnam. Phan Trong Trinh (1994) applied a variety of methods to study the Cenozoic stress field in Northwestern Vietnam and indi- 
cated that the second tectonic phase related to the tectonic stress field has a north - south compressive axis. This axis is consistent with the emission of stress originating in the eastern Himalayas, which is the result of the collision between Indian and Eurasian plates.

Table 2. Focal mechanism solutions of Northwestern Vietnam

\begin{tabular}{|c|c|c|c|c|c|c|c|c|}
\hline \multirow{2}{*}{ Date } & \multicolumn{2}{|c|}{ Location } & \multirow{2}{*}{ Ms } & \multicolumn{2}{|c|}{$\mathrm{P}$} & \multicolumn{2}{|c|}{$\mathrm{T}$} & \multirow{2}{*}{ Remark } \\
\hline & Lat. $\left(^{\circ}\right)$ & Lon. $\left({ }^{\circ}\right)$ & & Trend $\left({ }^{\circ}\right)$ & Plunge $\left(^{\circ}\right)$ & Trend $\left({ }^{\circ}\right)$ & Plunge $\left(^{\circ}\right)$ & \\
\hline $01 / 11 / 1935$ & 21.08 & 103.25 & 6.8 & 336 & 10 & 67 & 27 & \multirow{4}{*}{$\begin{array}{l}\text { Nguyen Van } \\
\text { Luong, } 1996\end{array}$} \\
\hline $13 / 8 / 1958$ & 20.02 & 105.57 & 5.2 & 170 & 5 & 265 & 32 & \\
\hline $24 / 6 / 1983$ & 21.29 & 106.31 & 6.7 & 166 & 10 & 74 & 11 & \\
\hline $22 / 5 / 1989$ & 20.8 & 105.28 & 4.9 & 175 & 15 & 279 & 8 & \\
\hline 06/10/1991 & 21.38 & 104.16 & 4.9 & 178 & 2 & 91 & 29 & Le Tu Son, 2000 \\
\hline $19 / 02 / 2001$ & 21.32 & 102.87 & 5.3 & 352 & 3 & 88 & 69 & Le Tu Son, 2004 \\
\hline $26 / 11 / 2009$ & 21.32 & 104.15 & 3.9 & 167 & 6 & 257 & 8 & \multirow{3}{*}{$\begin{array}{l}\text { Ha Thi Giang, } \\
2012\end{array}$} \\
\hline $19 / 9 / 2010$ & 20.22 & 104.94 & 4.2 & 351 & 7 & 259 & 19 & \\
\hline $30 / 12 / 2010$ & 20.83 & 103.49 & 4.8 & 177 & 9 & 270 & 13 & \\
\hline
\end{tabular}
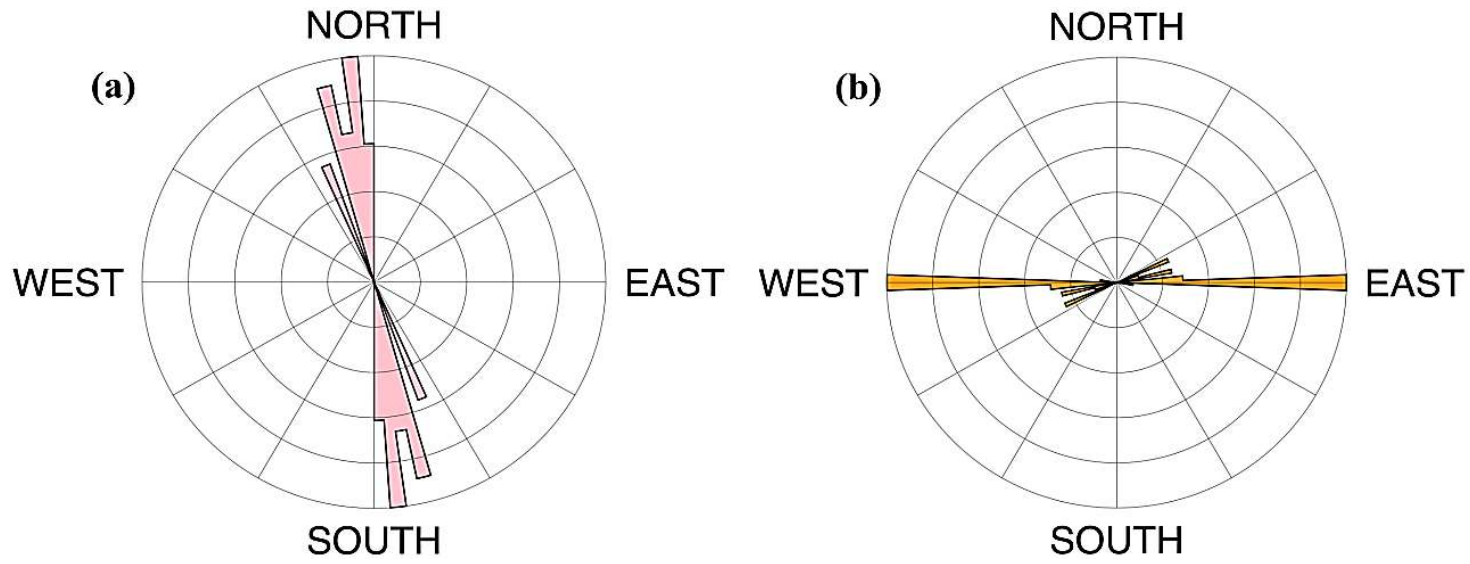

Figure 3. Rose diagrams of $\mathrm{P}$-axis directions (a) and T-axis directions (b) from 9 focal mechanisms in Northwestern Vietnam

The stress on each fault or in each small area is the result of effects of not only regional factors but also local factors (if any). The local stress can change in a short period of time when the local forces affecting the stress field change. Meanwhile, the regional stress is stable in the long period of time and has the continuous effect. Then, the fault state (with or without the effect of local stress) that is determined through geological surveys will be affected by the regional stress field. Therefore, the movement potential at geological survey points along major faults is calculated by using the axis $\sigma_{1}$ of the regional tectonic stress field.

\section{Results}

\subsection{The movement potential on the faults}

The elastic rebound theory was formulated by Reid $(1910,1911)$ to explain the movement of ground around the San Andreas fault that was caused by the San Francisco earthquake with $\mathrm{Mw}=7.8$ in 1906 (Reid 1910, 1911). From the measurements, Reid concluded that the earthquake must have been the result of the elastic rebound of previously accumulated elastic strain energy in the rocks on either side of the fault under the effect of the regional tectonic stress field. Thus, the condition for earthquake occurrence is the 
simultaneous appearance of two factors which are the fault with movement potential and the stress accumulation under the effect of the regional tectonic stress field. The locations in which the fault surface is extremely rough, rugged, undulating (horizontally or vertically) and the lithological environment is stable (highly mechanical properties in the rocks, low level of tectonic fracture) must be the ideal conditions for the stress accumulation of faults. In this case, it is assumed that the geological environment is homogeneous and isotropic, which means that the potential of stress accumulation of all faults is the same. Then, only the fault movement potential should be considered. Under the effect of regional tectonic stress field, which locations on the faults have the high movement potential or the low movement potential? In order to answer this question, the formula (3) is applied to evaluate the movement potential on major faults in Northwestern Vietnam. The results of FMP are presented in Table 1 and Figure 2.

The calculated results of FMP at survey points along major faults in the studied area show that the movement potential of these faults is mainly from medium to high $(40 / 60$ points with FMP $=0.6-0.9$ ). In particular, the faults in Dien Bien Phu area (Son La, Lai Chau - Dien Bien, Bung Lao - Da Bop, Tuan Giao - Nam Ty, Ma River, Muong Nhe, Muong Toong and Dien Bien - Pac Nua faults) have the highest movement potential $(\mathrm{FMP}=0.8-0.9)$. In addition, there are some locations with FMP $=0$ such as the segment of Son La fault in Moc Chau, Yen Chau, the segment of Ma River fault in Lang Chanh and Than Uyen fault in Than Uyen. By using the geostatistical method of Kriging regression, the FMP values distributed over the studied area are expressed as the color spectrum (Figure 4).

\subsection{The relationship between movement potential and seismic activities of the faults}

When evaluating the movement potential of major faults in Hong Kong - China, Lee et al. (1997) suggested that the faults with high movement potential have been likely to gen- erate large earthquakes and strong seismic activities. Thus, the seismic activities have a close relationship with the movement potential of faults. To examine this relationship in Northwestern Vietnam, a catalog of earthquakes in the period of 1277 - 2016 has been established, including 177 earthquakes with M = 4.0-6.8 (Appendix). The epicenter locations of these earthquakes have been represented on the color spectrum map of calculated results of FMP in the studied area (Figures 5a, b).

The results in Figures 5a, b show that at the locations with high movement potential of faults, the earthquakes occur frequently and strongly ( $\mathrm{M}=5.0$ - 6.8). Particularly, on the segment of Son La fault zone in Tuan Giao, Tua Chua, the movement potential has the highest value $(\mathrm{FMP}=0.9)$, corresponding to the occurrence of Tuan Giao earthquake with $M=6.8$ in 1983. Similarly, in Bung Lao - Da Bop and Tuan Giao - Nam Ty fault zones, intersections with Son La fault zone and Muong Ang area, the seismic activities occur frequently. On Lai Chau - Dien Bien fault zone, the earthquakes are mainly concentrated from the southwest of Dien Bien Phu city to the border with Laos and at the intersections with Son La and Upper Da River fault zones. The segment of Muong La - Bac Yen - Cho Bo fault zone in Muong La and Hoa Binh city has the relatively high movement potential (FMP $=0.7$ ) which is completely consistent with recent seismic activities such as the Ta Khoa earthquake with $\mathrm{M}=4.9$ in 1991 and the induced earthquake related to the water accumulation-discharge of Hoa Binh hydropower reservoir with $\mathrm{M}=4.9$ in 1989 . On the contrary, there are weak earthquakes or even no earthquakes at the locations with low movement potential of faults (FMP $<0.3)$ such as Than Uyen area on Than Uyen fault, Nghia Lo area on Nghia Lo - Hoa Binh fault, the areas near the border with Laos on Ma River and Son La faults and near the sea on the segment of Ma River fault (Figure 5a). 
Although the number of survey points in this study is not large (60 survey points) and their spatial distribution is uneven, the calcu- lated results of FMP demonstrate that the fault movement potential is closely related to the seismic activities in the studied area.

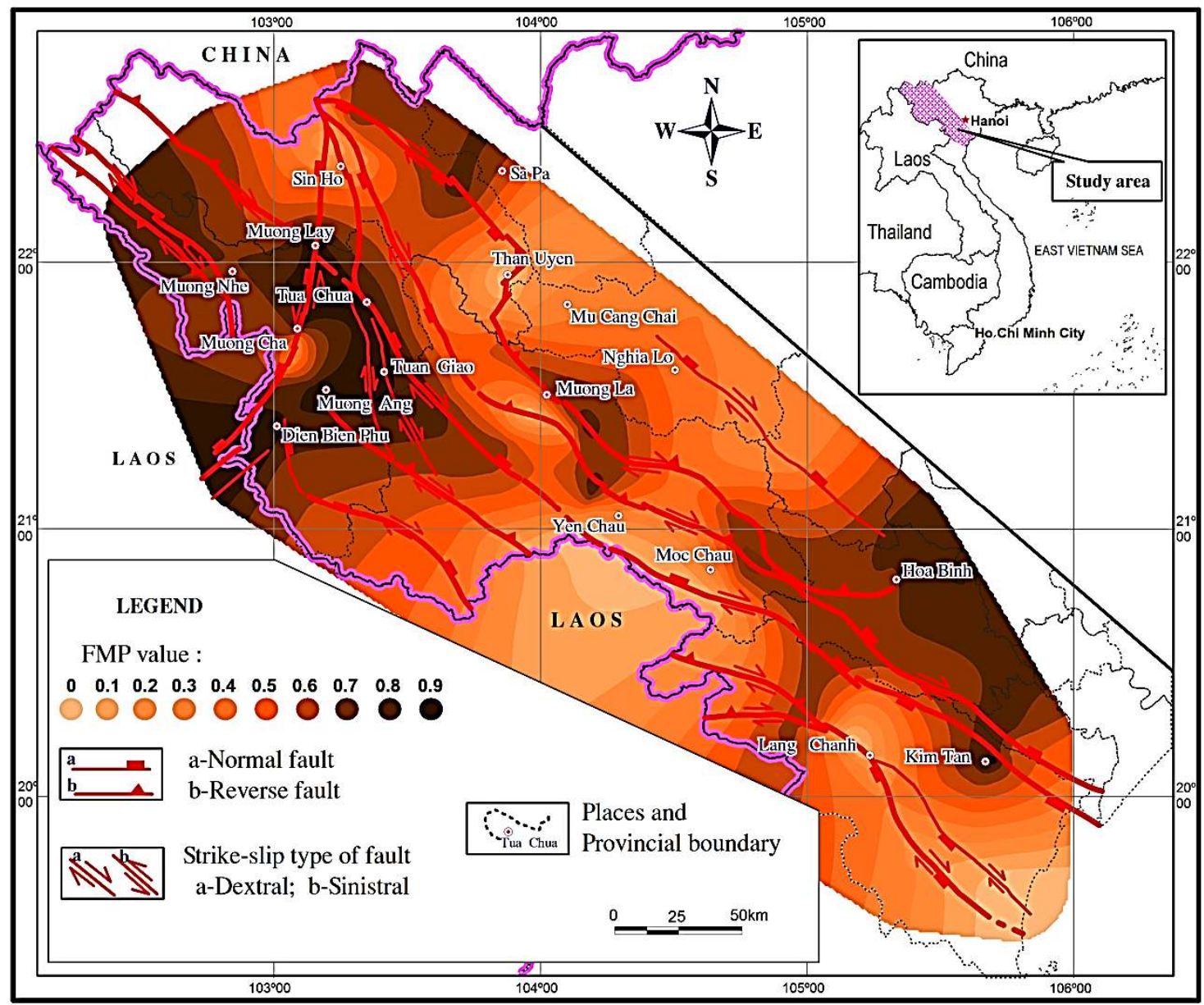

Figure 4. Map of fault movement potential in Northwestern Vietnam

\section{Discussion}

In Figure 5b, along Lai Chau - Dien Bien fault zone and some areas, the direction of fault is almost unchanged; however, FMP is very high at some locations (the area between Muong Lay and Muong Cha) and very low at other locations (Sin Ho area or the south of Muong Cha). It is because FMP depends not only on the direction of fault but also on its slip surface attitude. Therefore, even if the fault segments have the same direction but different slip surface attitudes, the FMP values will be different. In addition, on the small-scale map (Figure 5a), it can be seen that the fault extends and its direction is almost unchanged. Nevertheless, at the survey points on various fault segments, the directions of these segments are actually different. It indicates that the calculated result of FMP is the useful information for fault segmentation in the stage of contemporary tectonic activity.

On the color spectrum map of FMP and earthquake epicenters in Figures 5a, b, the difference between the fault movement potential and seismic activities can be seen at some lo- 
cations. It may be due to the effects of the following factors:

- There is a lack of survey points and they are unevenly distributed on the faults. This leads to errors in the data interpolation when representing the FMP distribution by color spectrum. In particular, there is no survey point on Fu May Tun fault near the Dien Bien earthquake in $1935(\mathrm{M}=6.7)$; however, the interpo- lation value shows that the movement potential of this fault zone is approximately 0.6. The FMP value is quite small compared to the magnitude of this earthquake. In the east of Hoa Binh city, the FMP value is relatively high according to the result of data interpolation that is affected by the high values of FMP at survey points in Nghia Lo - Hoa Binh fault zone, Da River fault and Son La fault (Figure 2).

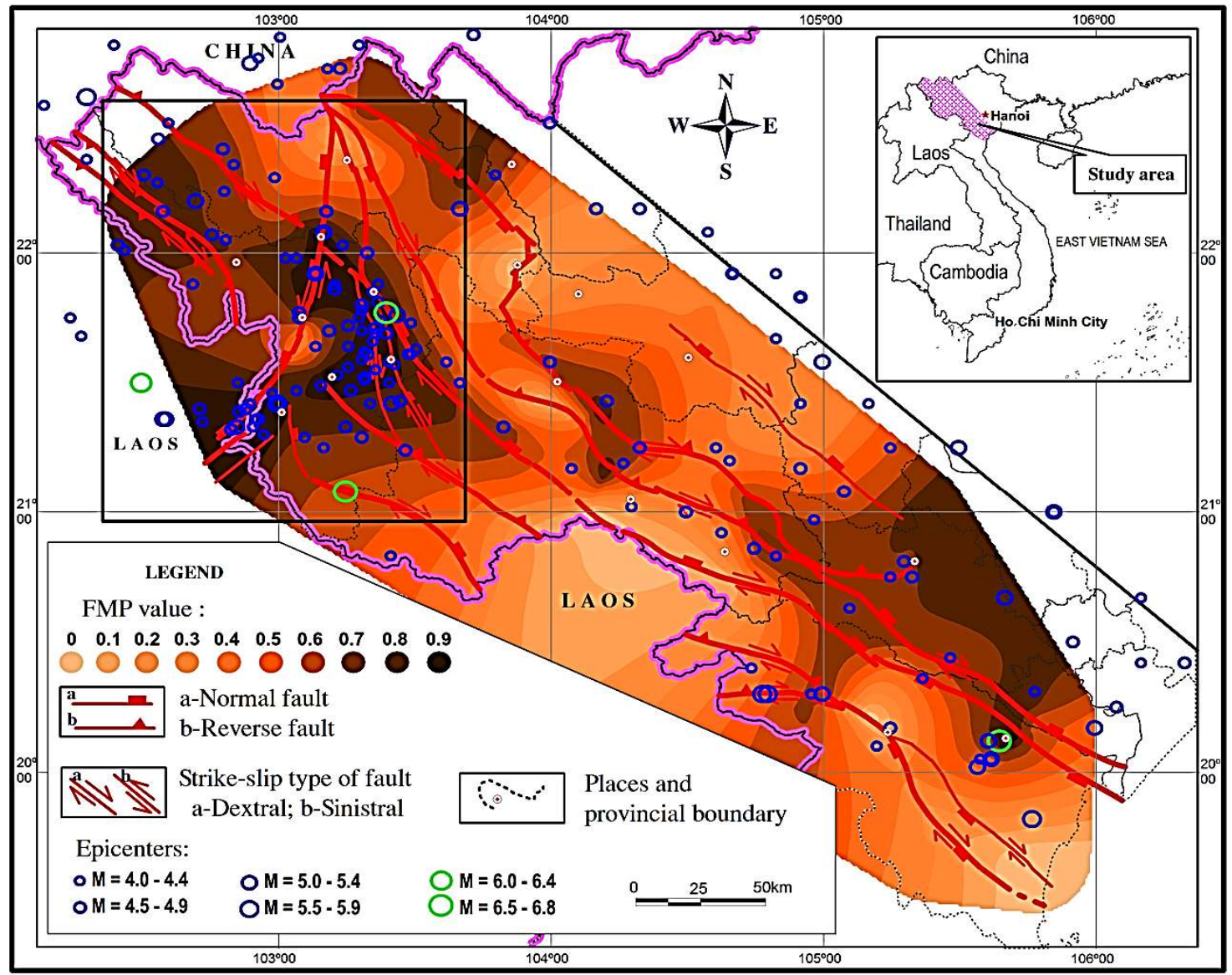

Figure 5. (a) Relationship between the movement potential of faults and the seismic activity in Northwestern Vietnam. Small rectangle bordering the Dien Bien Phu and Tuan Giao areas is depicted in Figure 5b; (b) Detail map of the movement potential of faults and the seismic activity in Dien Bien Phu and Tuan Giao areas

- The period of time in the catalog of earthquakes is not long enough; in addition, not all the earthquakes have been observed by instruments, several felt earthquakes have been recorded in the historical document and surveyed in public. Therefore, the determination of epicenter locations of these earthquakes is not highly accurate. 


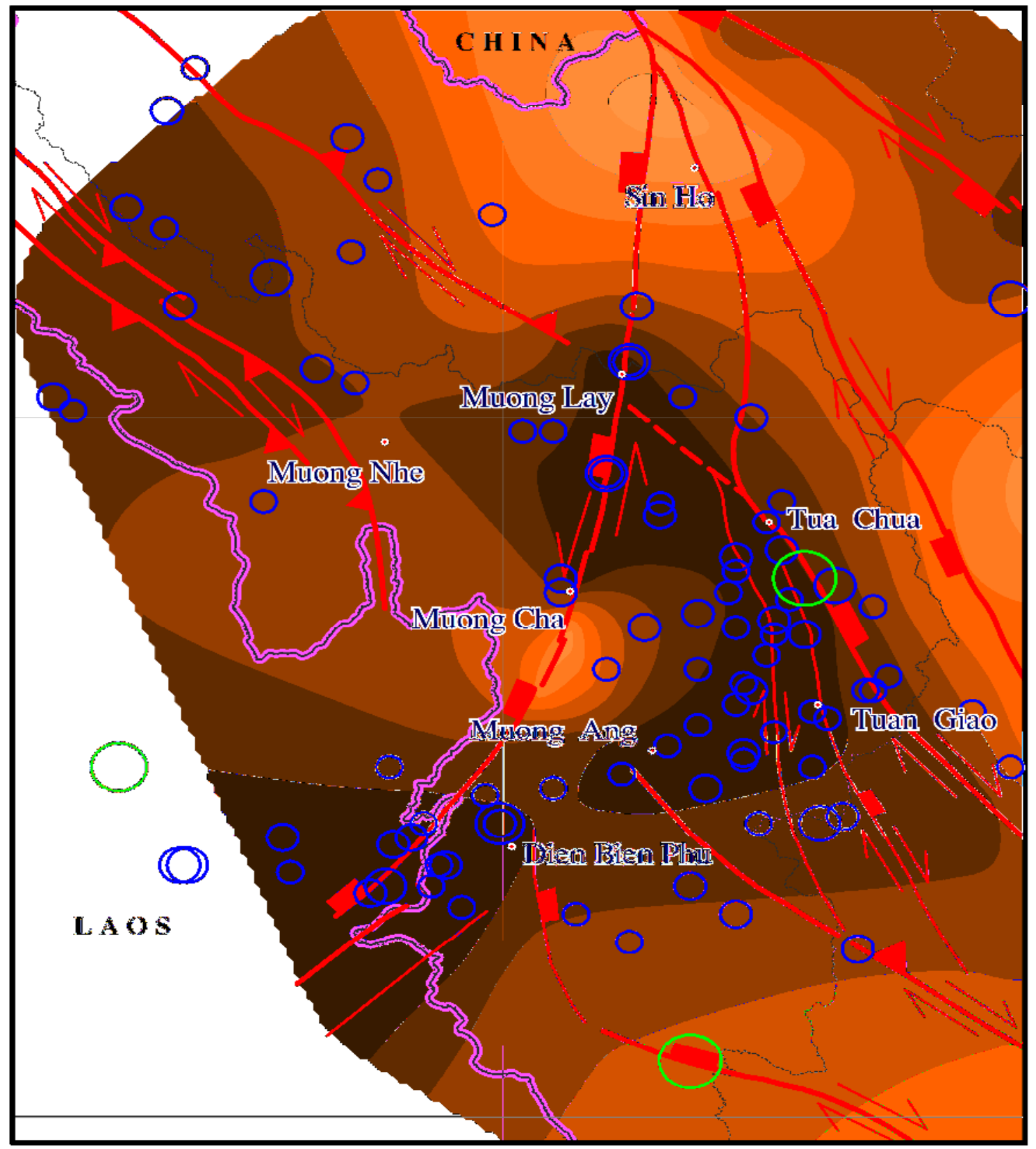

Figure 5b. Detail map of the movement potential of faults and the seismic activity in Dien Bien Phu and Tuan Giao areas

Despite these limitations, the calculated results of FMP in this study provide the information on the morphological characteristics of faults, the direction of contemporary compressive stress field and the medium (homogeneous, isotropic, elastic) inside and on the faults. The movement potential on various fault segments is different. This feature is due to the morphology of faults and the regional tectonic stress field. With the complete survey dataset on slip surface attitude of faults, the determination of FMP is significant 
for assessing the level of seismic activities on each part of the faults, serving the fault segmentation, establishment of seismogenic regions in the studied area, maximum earthquake prediction and seismic hazard assessment.

\section{Conclusions}

In Northwestern Vietnam, the movement potential of major fault zones such as Son $\mathrm{La}$, Ma River, Lai Chau - Dien Bien, Da River faults is assessed to be closely related to the seismic activities. The calculated results of FMP at 60 survey points along major faults in Northwestern Vietnam show that the fault movement potential is mainly from medium to high $(40 / 60$ points with FMP $=0.6-0.9)$. At the locations with high movement potential of faults (FMP $=0.8-0.9$, corresponding to the movement potential of $80-90 \%$ ), the seismic activities occur frequently, e.g. Kim Tan (Thanh Hoa), Tuan Giao (Dien Bien), Muong Ang (Dien Bien), Tua Chua (Dien Bien), Muong Nhe (Dien Bien) and the southwest of Dien Bien Phu city. At the locations with low movement potential of faults, weak earthquake or even no earthquake occur, e.g. Than Uyen (Lai Chau), Nghia Lo (Yen Bai), Mu Cang Chai (Yen Bai), Moc Chau (Son La), Yen Chau (Son La), Lang Chanh (Thanh Hoa).

\section{Acknowledgments}

We appreciate constructive criticism from two anonymous reviewers. This study has been financially supported by Vietnam Academy of Science and Technology under the research grant VAST.DLT 10/15-16.

\section{References}

Andeweg B., Vicente G. De , Cloetingh S., Giner J., and A. Muñoz Martin, 1999. Local stress field and intraplate deformation of Iberia: Variations in spatial and temporal interplay of regional stress sources, Tectonophysics, 305, 153-164.

Angelier J., Tarantola A., Valette B., Manoussis S., 1982. Inversion of field data in fault tectonics to obtain the regional stress - I. Single phase fault populations: a new method of computing the stress tensor, Geophys. J. R. astr. Soc., 69, 607-621.

Bui Van Duan, 2012. The study on contemporary tectonic characteristics and seismic activities in Muong La - Bac Yen fault zone. Master thesis, Hanoi University of Science, Hanoi (in Vietnamese).

Bui Van Duan, Ha Thi Giang, Nguyen Anh Duong, and Pham Dinh Nguyen, 2015. About factors related to the occurrence of earthquakes in the Song Tranh 2 hydropower area in period 2011-2014. J. Sci. of the Earth, 37(3), 228-240 (in Vietnamese, abstract in English)

Bott M.H.P., 1959. The mechanics of oblique slip faulting, Geol. Mag., 96, 109-117.

Findlay R. H. and Phan Trong Trinh, 1997. The structural setting of Song Ma region, Vietnam and the Indochina-South China plate boundary problem. Gondwana Research, 1(1), 11-33.

Ha Thi Giang, 2012. Determination of focal mechanisms of some earthquakes in North Vietnam using the broadband seismic data. Master thesis, Hanoi University of Science, Hanoi (in Vietnamese).

He S.H., 1989. The Effect of Orientation and Level of Principal Stress on Fault Movement. Crustal Deformation and Earthquake, 9, 44-52.

Le Tu Son, 2000. Focal mechanism of Ta Khoa, lai Chau and Muong Luan earthquake in North-West of Vietnam. J. Sci. of the Earth, 22(4), 355-360 (in Vietnamese, abstract English).

Le Tu Son, 2004. The Dien Bien earthquake, $\mathrm{Ms}=5.3$ on February 19, 2001. J. Sci. of the Earth, 26(2), 112121 (in Vietnamese, Abstract English).

Lee C.F., Hou J.J. and Ye H., 1997. The Movement Potential of the Major Faults in Hong Kong Area. Episodes, 20, 227-231.

Lokajicek T., Spicak A., and Waniek L., 1988. Tectonic Stress Orientation and the Seismic Regime of a Single Fault. Tectonophysics, 152, 297-302.

Maerten L., Gillespie P., Pollard D.D., 2002. Effects of local stress perturbation on secondary fault development. Journal of Structural Geology, 24, 145-153.

Mandal P., Manglik A., Singh R.N., 1997. Intraplate stress distribution induced by topography and crustal density heterogeneities beneath the Killari, India. Journal of Geophysical Research, 102, 11719-11729. 
Vietnam Journal of Earth Sciences, 39(3), 240-255

McKenzie D.P., 1969. The relation between fault plane solutions for earthquakes and the directions of the principal stresses, Bull. seism. Soc. Am., 59, 591-601.

Moghimi H., Arian M., and Sorbi A., 2015. Fault Movement Potential of Marzanabad Area, North Alborz, Iran. Open Journal of Geology, 5, 126-135.

Nguyen Anh Duong, Sagiya T., Kimata F., Tran D.T., Vy Q.H., Duong C.C., Nguyen X.B., and Nguyen D.X., 2013. Contemporary horizontal crustal movement estimation for northwestern Vietnam inferred from repeated GPS measurements, Earth Planets Space, 65(12), 1399-1410, DOI:10.5047/eps.2013.09.010.

Nguyen Anh Duong, Fumiaki Kimata, Tran Dinh To, Nguyen Dinh Xuyen, Pham Dinh Nguyen, Vi Quoc Hai, Duong Chi Cong, 2011. Contemporary horizontal movement estimation for Lai Chau - Dien Bien fault inferred from repeated GPS measurements in 2002 - 2010. J. Sci. of the Earth, 33(4), 690-694 (in Vietnamese, abstract English), DOI: $10.15625 / 0866-7187 / 33 / 4 / 556$.

Nguyen Dinh Xuyen et al., 2004a. Study on earthquake prediction and ground motion in Vietnam. Final report of the National project 2000-2002. Institute of Geophysics, Vietnam Academy of Science and Technology, Hanoi (in Vietnamese).

Nguyen Dinh Xuyen et al., 2004b. Seismic hazard assessment and micro-zonation of Lai Chau hydropower dam area. Final report of the technical design stage. Institute of Geophysics, Vietnam Academy of Science and Technology, Hanoi (in Vietnamese).

Nguyen Ngoc Thuy et al., 2005a. Detailed earthquake zoning for northwestern Vietnam, National Project on science and technology, KC08-10, Period 20012005, Institute of Geophysics, Hanoi, Vietnam, 2005 (in Vietnamese).

Nguyen Ngoc Thuy et al., 2006. Seismic hazard assessment and micro-zonation of Van Chan hydropower dam area. Final report of the technical design stage. Institute of Geophysics, Vietnam Academy of Science and Technology, Hanoi (in Vietnamese).

Nguyen Ngoc Thuy et al., 2008. Seismic hazard assessment, design earthquake parameters and micro-zonation of Hua $\mathrm{Na}$ hydropower dam area. Final report of the technical design stage. Institute of
Geophysics, Vietnam Academy of Science and Technology, Hanoi (in Vietnamese).

Nguyen Trong Yem, 1996. Tectonic stress field in Cenozoic in Vietnam. Journal of Geology (Hanoi), series A 236, 9-10 (in Vietnamese).

Nguyen Van Hung, 2002. Some basic features of neotectonic faults in Northwestern Vietnam. Geological Doctoral Thesis, Institute of Geological Sciences, National Center for Natural Science and Technology, Hanoi (in Vietnamese).

Nguyen Van Hung, Hoang Quang Vinh, 2004. On activity of neotectonic faults in Northwestern Vietnam. Journal of Geology (Hanoi), series A(285), 38-48 (in Vietnamese).

Nguyen Van Luong, 1996. Results of determining focal mechanism by means of synthetic macroseismic field method in Vietnam. J. Sci. of the Earth, 18 (3), 145-152.

Nguyen Van Luong and Bui Cong Que, 1997. Characteristics of the tectonic stress field of crust in the East Sea and adjacent areas. J. Sci. of the Earth, 19(1), 30-38 (in Vietnamese, abstract English).

Nguyen Van Vuong, Vu Van Tich, Nguyen Ngoc Thuy, Bui Van Duan, 2004. Testing on the zonation and prediction of contemporary crustal movement features in Northwestern Vietnam based on the interrelation between the regional tectonic stress field and some fault systems. Journal of Geology (Hanoi), series A(285), 49-56 (in Vietnamese).

Phan Trong Trinh, 1993. An inverse problem for the determination of the stress tensor from polyphased fault sets and earthquake focal mechanisms. Tectonophysics, 393-411.

Phan Trong Trinh, 1994. Cenozoic stress field in the Northwestern region of Vietnam. Journal of Geology (Hanoi), series B (3-4), 12-18.

Phan Trong Trinh, 2012. Neo-tectonics and contemporary geodynamics in Vietnam sea area and adjacency. Science and Technology Publishing House, Hanoi, 330p (in Vietnamese).

Phan Trong Trinh, Hoang Quang Vinh, Nguyen Van Huong, Ngo Van Liem, 2013. Active fault segmentation and seismic hazard in Hoa-Binh reservoir, Vietnam. Central European Journal of Geosciences, 5(2). 223-235. DOI: 10.2478/s13533-012-0128-5.

Phan Trong Trinh, Ngo Van Liem, Nguyen Van Huong, Hoang Quang Vinh, Bui Van Thom, Bui Thi Thao, Mai Thanh Tan, Nguyen Hoang, 2012. Late Quater- 
nary tectonics and seismotectonics along the Red River fault zone, North Vietnam. Earth Science Reviews 114 (3-4), 224-235.

Phan Trong Trinh, Nguyen Trong Y., Nguyen H., Lacassin R., Tapponnier P., Leloup H. \& Winter Th., 1994. Active faulting and tectonics of North Vietnam. International Workshop on Seismic Hazard in SE Asia, Hanoi, Vietnam.

Reid H.F., 1910. The mechanics of the earthquake. In A.C. Lawson (Ed.), The California earthquake of April 18, 1906, Report of the State Earthquake Investigation Commission, Vol.II., Washington, DC: Carnegie Institute of Washington, 3-55.

Reid H.F., 1911. The elastic rebound theory of earthquakes. Bulletin of the Department of Geology, University of California Publications 6(19), 413-444.

Roman D.C. and Heron P., 2007. Effect of regional tectonic setting on local fault response to episodes of volcanic activity, Geophysical Research Letters, 34, L13310.

Simons W.J.F., Socquet A., Vigny C., Ambrosius B.A.C., Haji Abu S., Chawat Promthong, Subarya C., Sasito D. A., Matheussen S., Morgan P., and Spakman W., 2007. A decade of GPS in Southeast Asia: Resolving Sundaland motion and boundaries, J. Geophys. Res., 112, B06420, DOI:10.1029/2005JB003868.

Sorbi A., Arian M., Pourkermani M., 2009. The movement potential evaluation of the major
Quaternary faults in Tehran Quadrangle. Journal of Sciences - Islamic Azad University (JSIAU), 19(73), 176-182.

Tingay M., Morley C., King R., Hillis R., Coblentz D. \& Hall R., 2010. Present-day stress field of Southeast Asia. Tectonophysics, 482(1-4), 92-104.

Tran Van Thang et al., 2012. Study on the relationship between geological hazards and modern activity of sub-longitudinal tectonic fracture zones in Northwestern Vietnam. Final report of VAST project (2008-2009). Institute of Geological Sciences, Vietnam Academy of Science and Technology, Hanoi (in Vietnamese).

Tuttle M.P., Schweig E.S., Sims J.D., Lafferty R.H., Wolf L.W., and Haynes M. L., 2002. The earthquake potential of the New Madrid seismic zone. Bull. Seismol. Soc. Am. 92, 2080-2089.

Van Duc Tung, 2011. Development characteristics of the Lai Chau - Dien Bien fault zone. Geological Doctoral Thesis, Institute of Geological Sciences, Vietnam Academy of Science and Technology, Hanoi (in Vietnamese, Abstract English).

Winter Th., Phan Trong Trinh, Lacassin R., Nguyen Trong Y., Costaz J., 1994. Advantages of a deterministic approach of seismic risk for dam design: the Hoa Binh Dam case (Vietnam). Proceedings of the International Workshop on Seismic Hazard in SE Asia, Hanoi, Vietnam, 249-254. 